\title{
The Adsorption Mechanism of Modified Activated Carbon on Phenol
}

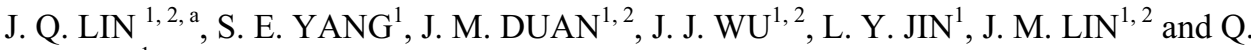 \\ L. DENG ${ }^{1}$ \\ 1. Department of Environmental Engineering, College of Food and Biological Engineering, Jimei \\ University, Xiamen 361021, China; \\ 2. Institute of Environment Engineering, Jimei University, Xiamen 361021, China \\ a jqlin@jmu.edu.cn ${ }^{1}$ (Corresponding Author)
}

\begin{abstract}
Modified activated carbon was prepared by thermal treatment at high temperature under nitrogen flow. The surface properties of the activated carbon were characterized by Boehm titration, BET and point of zero charge determination. The adsorption mechanism of phenol on modified activated carbon was explained and the adsorption capacity of modified activated carbon for phenol when compared to plain activated carbon was evaluated through the analysis of adsorption isotherms, thermodynamic and kinetic properties. Results shows that after modification the surface alkaline property and $\mathrm{pHpzc}$ value of the activated carbon increase and the surface oxygen-containing functional groups decrease. The adsorption processes of the plain and modified carbon fit with Langmuir isotherm equation well, and the maximum adsorption capacity increase from $123.46,111.11,103.09 \mathrm{mg} / \mathrm{g}$ to $192.31,178.57$, $163,93 \mathrm{mg} / \mathrm{g}$ under 15,25 and $35^{\circ} \mathrm{C}$ after modification, respectively. Thermodynamic parameters show that the adsorption of phenol on activated carbon is a spontaneously exothermic process of entropy reduction, implying that the adsorption is a physical adsorption. The adsorption of phenol on activated carbon follows the pseudo-second-order kinetics ( $\mathrm{R} 2>0.99)$. The optimum $\mathrm{pH}$ of adsorption is $6 \sim 8$.
\end{abstract}

\section{Introduction}

Phenol is widely used as intermediates in the chemical synthesis of plastics, colors, pesticides, etc. and spice synthesis in food industry. Degradation of these substances means the existence of phenol in the environment that can lead to pollution [1,2]. Phenol is a toxic compound that even at an extremely low concentration can cause unpleasant taste and odor of drinking water. So it is considered as one of the priority pollutants in the drinking water by the standard of China, European and American countries. Different methods designed to remove phenol have been proposed, such as adsorption, electrochemical precipitation, ion exchange, reverse osmosis, and solvent extraction [3] etc. Among these methods, adsorption is the best and most frequently used method. It is well known that the porosity of adsorbent is the key to contaminants adsorption. Due to its large surface area and

\footnotetext{
* Corresponding author: jqlin@jmu.edu.cn
} 
porosity, activated carbon is the most commonly employed adsorbent for the removal of contaminants in wastewater treatment [2]. The adsorption process depends on several factors, including the nature of the adsorbent [4] and adsorbate, adsorption conditions [5, 6]. Relatively large amounts of studies have described behavior of activated carbons with oxygen-containing basic functional surface groups that in general cause enhanced sorption of phenolic compounds in addition, removal of acidic oxygen-containing groups from activated carbons was suggested to be a way to increase absorbability of phenol $[7,8,9]$. Based on this theory, many modification methods are proposed, such as pretreatment with acid [10], ammonia [11] and saturated urea solutions [12], respectively, followed with thermal treatment. However, there are just a few researches working on thermal treatment of activated carbons without any pretreatment. And the adsorption mechanism of phenol on the thermal treated activated carbon is barely elaborated.

The objective of this paper is to explain the adsorption mechanism of phenol on modified activated carbons and evaluate the adsorption capacity of modified activated carbon for phenol when compared to plain activated carbon. Langmuir and Freundlich model have been applied to ascertain the nature of the interaction between the adsorbent and adsorbate. The Kinetic modeling of pseudo-first-order and pseudo-second-order models as well as the intraparticle model has been used to describe the reaction order of adsorption systems based on solution concentration.

\section{Materials and Methods}

Materials and Equipment: The commercially available coconut shell activated carbons used in the experiment was supplied by Gongyi Longtai Water Purification Packing Factory (in China). Firstly, to sieve the commercially available activated carbons and select carbons in 20-40 mesh (the diameter was $0.45-0.9 \mathrm{~mm}$ ). Secondly, the activated carbons were washed with deionized water thoroughly until $\mathrm{pH}$ of the filtrate was constant. Finally, the activated carbons were dried in electro-thermostatic blast oven at $100{ }^{\circ} \mathrm{C}$ for $4 \mathrm{~h}$ and collected in desiccator (denoted as AC).

Main chemicals and equipment: Except sodium hydroxide, concentrated hydrochloric acid, sodium bicarbonate were guarantee reagent, all chemicals were analytically pure. Vacuum tube furnace (GSL-1100X, China), incubator shakers (HYW-2112, China), UV-visible spectrophotometer (UV-755B, China), scanning electron microscope (S-4800, Japan), pH meter (HANNA pH211, China), Surface Area and Porosity Analyzer (Microme-ritics ASAP 2020).

The Preparation and Characterization of Activated Carbons: Placing around $6 \mathrm{~g}$ pretreated activated carbon in a tubular quartz reactor of vacuum tube furnace. The sample was heated in nitrogen flow using a heating rate of $10^{\circ} \mathrm{C} / \mathrm{min}$ to $850^{\circ} \mathrm{C}$ and held for $1 \mathrm{~h}$. Then the sample was cooled down to room temperature. Finally, the sample was collected in a sealed bag, stored in a desiccator (denoted as MAC). And the surface properties of activated carbon are characterized by Boehm titration $[13,14]$, Determination of Point of Zero Charge $\left(\mathrm{pH}_{\mathrm{pzc}}\right)$ [15] and Surface Area and Porosity Analyzer (ASAP 2020, American), respectively.

Batch Experiment: Batch experiments for optimization of process parameters were carried out in $250 \mathrm{~mL}$ round bottom flasks with working volume of $100 \mathrm{~mL}$ at $150 \mathrm{rpm}$ in an incubator shaker. Initial phenol concentration was selected as $1000 \mathrm{mg} / \mathrm{L}$. Contact time was selected from a range of time 5-600 min and the adsorption equilibrium time was obtained when the adsorption equilibrium was achieved. Activated carbon dose of 0.1-5.0 $\mathrm{g} / \mathrm{L}$ were used for adsorption of phenol and optimum dose was decided on the basis of maximum adsorption capacity. The optimum $\mathrm{pH}$ was selected from a range of $\mathrm{pH}$ 2-11. Afterwards, each mixture was filtered by $0.45 \mu \mathrm{m}$ microfiltration membrane to separate 
activated carbon and contents of phenol were measured in obtained filtrates with use of UV-visible spectrophotometer (UV-755B, China) [9] at wavelength of $270 \mathrm{~nm}$.

The amount of phenol adsorbed per unit mass of the adsorbent was evaluated by the following mass balance equation:

$$
q_{t}=\frac{V\left(C_{0}-C_{t}\right)}{W}
$$

Where $\mathrm{C}_{0}$ was the initial phenol concentration $(\mathrm{mg} / \mathrm{L})$ and $\mathrm{C}_{\mathrm{t}}$ was phenol concentration $(\mathrm{mg} / \mathrm{L})$ at given time $\mathrm{t}, \mathrm{V}$ was the volume of the solution $(\mathrm{L})$ and $\mathrm{W}$ was the mass of the adsorbent used (g).

All the experiments were carried out in triplicates and average results were used. Except the experiment of effect of $\mathrm{pH}$ on adsorption, the remainder experiments had no manual adjustment of solution $\mathrm{pH}$.

\section{Results and Discussion}

The Comparison of AC and MAC Adsorption Performance for Phenol: Fig.1 showed time course of phenol adsorption on AC and MAC. Compared with AC, the adsorption capacity of phenol on MAC enhanced significantly, the maximum adsorption capacity of phenol $\left(q_{m}\right)$ increased from $93.96 \mathrm{mg} / \mathrm{g}$ to $132.30 \mathrm{mg} / \mathrm{g}$. And the adsorption equilibrium was achieved after $360 \mathrm{~min}$.

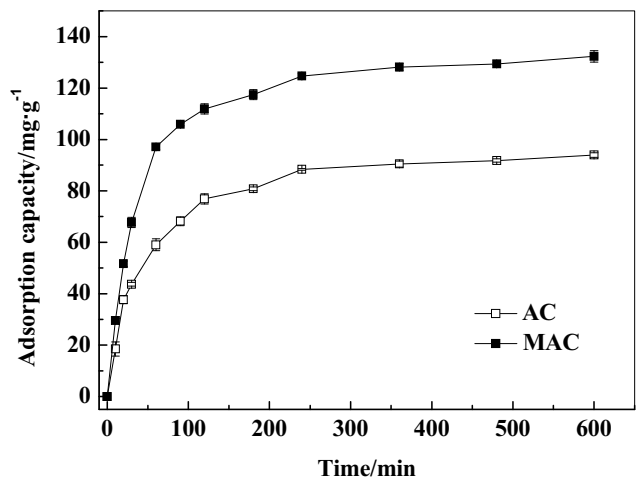

Fig.1 Time course of phenol adsorption on $\mathrm{AC}$ and MAC

It had suggested that the porous structures, in terms of area, pore volume, and pore distribution, were important properties of activated carbon and determined the performance of carbon during adsorption [5, 6]. C.-T. Hsieh et al [5] found that with the increase of the specific surface area of the activated carbon, the adsorption capacity of phenol increased. Meanwhile, other studies had shown that in liquid phase adsorption, micropores were the major provider of adsorption sites, and played an important role in the activated carbon adsorption of phenol $[6,9,16]$. Pore structure parameters of AC and MAC measured by the ASAP 2020 surface area and pore size analyzer were shown in Tab.1. It showed that after modification, the specific surface area and micropore volume of the activated carbon 
increased from 860.1 to $1000.4 \mathrm{~m}^{2} / \mathrm{g}, 0.279$ to $0.306 \mathrm{~cm}^{3} / \mathrm{g}$, respectively. The total porosity, mesopore volume and pore average size also increased. As it well known, the diameter of phenol was $0.62 \mathrm{~nm}$ [9], the increased pore size of the activated carbon was obviously beneficial for the phenol transmission and adsorption on activated carbons. It was likely concluded that thermal treatment at high temperature under a nitrogen atmosphere was an effective method for phenol adsorption, because of the increasing specific surface area and the formation of the pore structure.

Table 1 Pore Parameters Of Ac And Mac

\begin{tabular}{cccccc}
\hline Types & $\begin{array}{c}\text { BET SA } \\
\left(\mathrm{m}^{2} / \mathrm{g}\right)\end{array}$ & $\begin{array}{c}\text { Total pore } \\
\left(\mathrm{cm}^{3} / \mathrm{g}\right)\end{array}$ & $\begin{array}{c}\text { Mesopore } \\
\left(\mathrm{cm}^{3} / \mathrm{g}\right)\end{array}$ & $\begin{array}{c}\text { Micropore } \\
\left(\mathrm{cm}^{3} / \mathrm{g}\right)\end{array}$ & $\begin{array}{c}\text { Ave. pore } \\
\text { diameter }(\mathrm{nm})\end{array}$ \\
\hline $\mathrm{AC}$ & 860.1 & 0.429 & 0.097 & 0.279 & 1.994 \\
$\mathrm{MAC}$ & 1000.4 & 0.505 & 0.129 & 0.306 & 2.021 \\
\hline
\end{tabular}

In order to accurately describe the adsorptive reaction of phenol on activated carbon, the pseudo first-order, pseudo second-order model and intraparticle model [17, 18, 19] were used to fit the adsorption process of phenol on AC and MAC. The formulas were as bellow:

$$
\text { Pseudo first-order: } q_{t}=q_{e}\left(1-e^{-k_{1} t}\right)
$$

$$
\text { Pseudo second-order: } q_{t}=\frac{q_{e}^{2} \cdot K_{2} \cdot t}{1+q_{e} \cdot K_{2} \cdot t}
$$

Weber and Morris intraparticle model: $q_{t}=k_{i d} t^{1 / 2}$

Where $q_{e}$ and $q_{t}$ are the amount of phenol adsorbed per unit mass of the adsorbent $(\mathrm{mg} / \mathrm{g})$ at adsorption equilibrium and any time t, respectively. $K_{1}$ and $K_{2}$ are rates constant of pseudo first-order and pseudo second-order kinetics equation. $k_{i d}$ is pore diffusion rate constant.

To fit the pseudo first-order kinetics equation a plot of $\ln \left(q_{e}-q_{t}\right)$ vs. $\mathrm{t}$ was drawn (Fig. 2-1), from the linear slope and intercept, it could calculate the $K_{l}$ and $q_{e}$. In the same ways, a plot of $\mathrm{t} / \mathrm{q}_{\mathrm{t}}$ vs. $\mathrm{t}$ was drawn (Fig. 2-2) to get $K_{2}, q_{e}$ and a plot of $q_{t} \mathrm{vs} . t^{1 / 2}$ was drawn (Fig. $2-3)$ to get $k_{i d}$. The parameters of adsorption kinetics were showed in Tab. 2 and Tab. 3, respectively. 


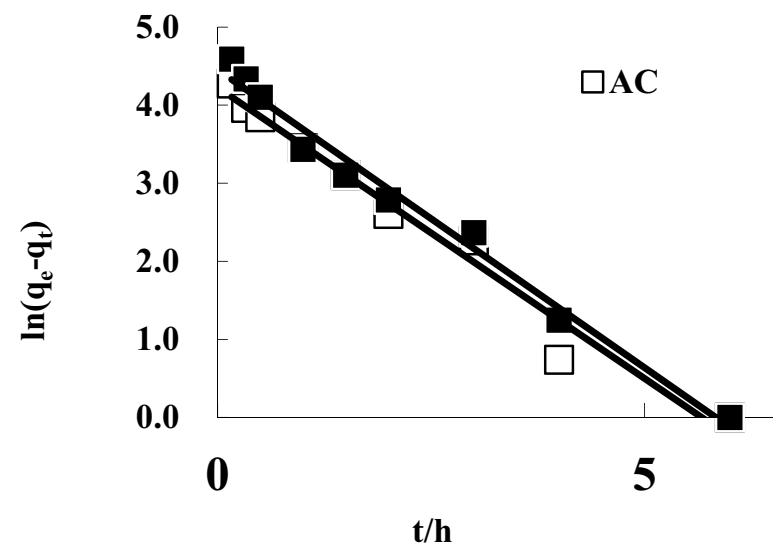

Fig.2-1 Linear fitting of pseudo first-order for phenol adsorption onto ACs

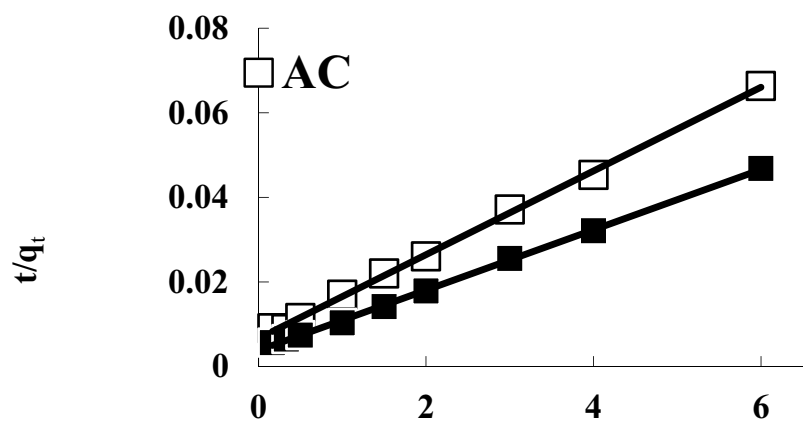

$\mathbf{t} / \mathbf{h}$

Fig.2-2 Linear fitting of second-order for phenol adsorption onto ACs

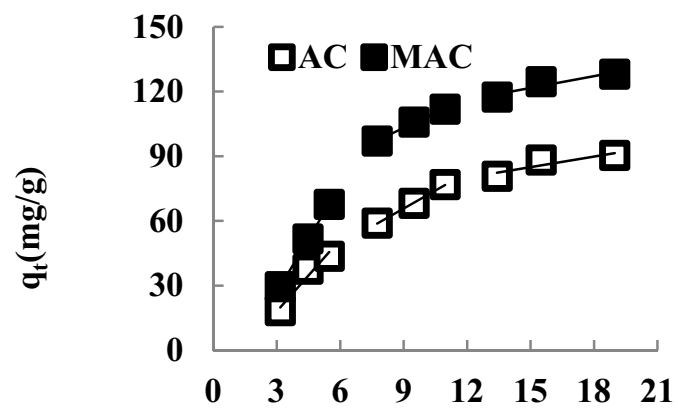

$\mathbf{t}^{0.5} / \mathrm{min}$

Fig.2-3 Linear fitting of intraparticle model for phenol adsorption onto ACs 


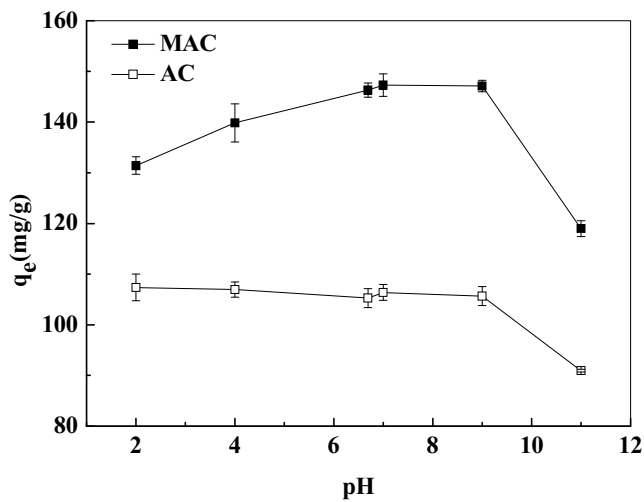

Fig.3 Adsorption amount of phenol on $\mathrm{AC}$ and $\mathrm{MAC}$ under different $\mathrm{pH}$ value conditions

Table 2 Parameters Of Adsorption Kinetics For Phenol Adsorption Onto Activated Carbons

\begin{tabular}{|c|c|c|c|c|c|c|c|c|c|}
\hline \multirow[b]{2}{*}{ Types } & \multirow{2}{*}{$\begin{array}{c}q_{e}(\exp )^{\mathrm{a}} \\
(\mathrm{mg} / \mathrm{g})\end{array}$} & \multicolumn{3}{|c|}{ pseudo first-order model } & \multicolumn{5}{|c|}{ pseudo second-order model } \\
\hline & & $\begin{array}{c}K_{I} \\
(1 / \mathrm{h})\end{array}$ & $\begin{array}{l}q_{e}(\mathrm{cal})^{\mathrm{b}} \\
(\mathrm{mg} / \mathrm{g})\end{array}$ & $R^{2}$ & $\begin{array}{l}K_{2} \times 10^{-3} \\
\mathrm{~g} /(\mathrm{mg} \cdot \mathrm{h})\end{array}$ & $\begin{array}{l}q_{e}(\mathrm{cal})^{\mathrm{b}} \\
(\mathrm{mg} / \mathrm{g})\end{array}$ & $\begin{array}{l}t_{1 / 2} \\
(\mathrm{~h})\end{array}$ & $\begin{array}{c}h \\
(\mathrm{mg} / \mathrm{g} \cdot \mathrm{h})\end{array}$ & $R^{2}$ \\
\hline $\mathrm{AC}$ & 90.44 & 0.7455 & 68.51 & 0.9747 & 14.6284 & 101.01 & 0.68 & 149.25 & 0.9987 \\
\hline MAC & 128.11 & 0.7634 & 85.97 & 0.9836 & 13.2658 & 140.85 & 0.54 & 263.16 & 0.9992 \\
\hline
\end{tabular}

Table 3 Intraparticle Model Parameters Of Phenol Adsorption On Activated Carbons

\begin{tabular}{ccccccc}
\hline \multirow{2}{*}{ Types } & \multicolumn{6}{c}{ Intraparticle model } \\
\cline { 2 - 7 } & $K_{i d 1}$ & $\mathrm{R}^{2}$ & $K_{i d 2}$ & $\mathrm{R}^{2}$ & $K_{i d 3}$ & $\mathrm{R}^{2}$ \\
\hline $\mathrm{AC}$ & 11.079 & 0.953 & 5.566 & 0.999 & 1.620 & 0.802 \\
$\mathrm{MAC}$ & 16.481 & 0.999 & 4.624 & 0.997 & 1.822 & 0.887 \\
\hline
\end{tabular}

Tab. 2 showed that the process of phenol adsorption on AC and MAC was well-fitting pseudo second-order kinetics equation for the better linear correlation coefficient $\left(\mathrm{R}^{2}>\right.$ 0.99), the adsorption capacity calculated from equation was $101.01 \mathrm{mg} / \mathrm{g}$ and $140.85 \mathrm{mg} / \mathrm{g}$ respectively, which was highly consistent with the experimental data. Furthermore, the half adsorption time was shorten from $0.68 h$ to $0.54 h$ and the initial adsorption rate was increased from $149.25 \mathrm{mg} / \mathrm{g} \cdot \mathrm{h}$ to $263.16 \mathrm{mg} / \mathrm{g} \cdot \mathrm{h}$ after modification. It could be concluded that it was the thermal treatment at high temperature under $\mathrm{N}_{2}$ flow that made the activated carbon having a higher adsorption capacity for phenol, which was consistent with the relatively high adsorption rate.

As can be seen from Fig.2-3, the intraparticle model generated a multilinear curve for adsorption of phenol on AC and MAC. Accordingly, the plot could be described by three linear curves with different values of rate constants, which indicated that phenol adsorption on ACs were composed of three consecutive process including film diffusion, intraparticle diffusion and surface adsorption [20]. And from Table 3, it could be observed that the 
values of rate constants of AC and MAC were all decreased from 11.079 to 1.620 and 16.481 to 1.822 , respectively, as time progresses. This implied that the adsorption of phenol on ACs were fast during the initial period of reaction because of the vacant and available adsorption sites. As the reaction going on, competition for the remaining adsorption sites increased, resulting in a decrease in rate of adsorption.

Adsorption isotherms of phenol on activated carbons at different temperatures: The effect of reaction temperature and phenol initial concentration on the adsorption capacity of activated carbon showed in Fig. 3.

Two kinds of adsorption isotherm models: Langmuir and Freundlich models [1, 21] were used to fit the adsorption process of phenol on activated carbons at different temperatures. The linear expressions of Langmuir and Freundlich equations were as below.

Langmuir linear equation:

$$
\frac{C_{e}}{q_{e}}=\frac{1}{q_{m}} C_{e}+\frac{1}{q_{m} K_{L}}
$$

Freundlich linear equation:

$$
\ln q_{e}=\frac{1}{n} \ln C_{e}+\ln K_{F}
$$

Where $q_{m}$ was the monolayer theoretical maximum adsorption capacity $(\mathrm{mg} / \mathrm{g}), K_{L}$ was the Adsorption Strength, $K_{F}$ was the adsorption equilibrium constant; $\mathrm{n}$ was absorption index.

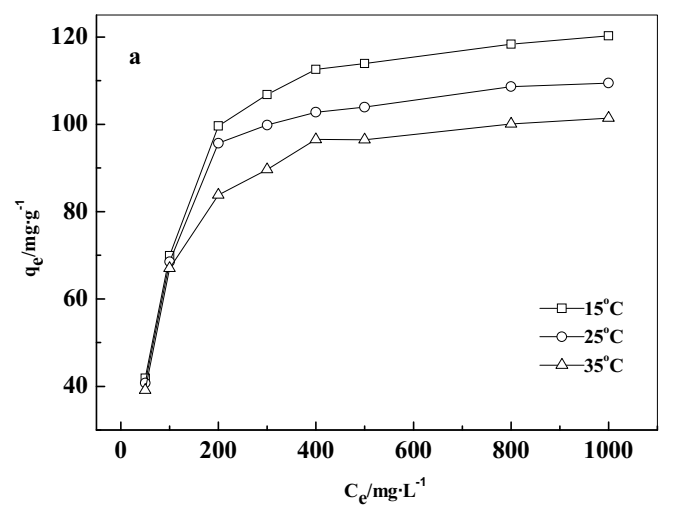




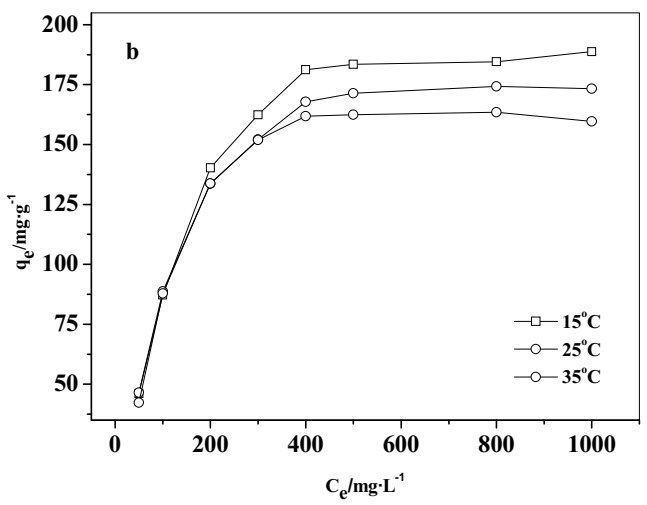

Fig. 4 Adsorption isotherms of phenol at different temperature on $\mathrm{AC}$ (a) and MAC (b)

The fitting results showed in the Tab.4, the adsorption processes of phenol on AC and MAC were well fitted Langmuir model $\left(\mathrm{R}^{2}>0.99\right)$. And the maximum adsorption capacity was decreased with the increase of the temperature, it conclude that low temperature was benefit for phenol adsorption on activated carbons.

In order to analyze the energy change of activated carbon adsorption process of phenol deeply, the adsorption thermodynamic of the adsorption process was analyzed. The free energy change $\left(\Delta G^{0}\right)$, enthalpy change $\left(\Delta H^{0}\right)$ and entropy $\left(\Delta S^{0}\right)$ value could be determined separately $[21,22]$ by the following equations $(7,8,9)$. The results showed in Tab. 5 .

$$
K_{d}=\frac{q_{e}}{C_{e}}
$$

$$
\Delta G^{0}=-R T \ln k_{d}
$$

$$
\ln k_{d}=-\frac{\Delta H^{0}}{R T}+\frac{\Delta S^{0}}{R}
$$


Table 4 Parameters Of Langmuir And Freundlich Adsorption Isotherms

\begin{tabular}{|c|c|c|c|c|c|c|c|}
\hline \multirow[b]{2}{*}{ Types } & \multirow{2}{*}{$\begin{array}{c}\text { Temperature } \\
\left({ }^{\circ} \mathrm{C}\right)\end{array}$} & \multicolumn{3}{|c|}{ Langmuir } & \multicolumn{3}{|c|}{ Freundlich } \\
\hline & & $\begin{array}{c}q_{m} \\
(\mathrm{mg} / \mathrm{g})\end{array}$ & $\begin{array}{c}K_{L} \\
(\mathrm{~L} / \mathrm{mg})\end{array}$ & $R^{2}$ & $K_{F}$ & $1 / \mathrm{n}$ & $R^{2}$ \\
\hline \multirow{3}{*}{$\mathrm{AC}$} & 15 & 123.457 & 0.0419 & 0.9998 & 31.1122 & 0.2178 & 0.906 \\
\hline & 25 & 111.110 & 0.0480 & 0.9998 & 31.0128 & 0.2039 & 0.8733 \\
\hline & 35 & 103.093 & 0.0418 & 0.9997 & 29.1426 & 0.1993 & 0.8817 \\
\hline \multirow{3}{*}{ MAC } & 15 & 192.308 & 0.0576 & 0.9997 & 41.3015 & 0.2538 & 0.8999 \\
\hline & 25 & 178.571 & 0.0661 & 0.9996 & 43.9609 & 0.2297 & 0.8987 \\
\hline & 35 & 163.934 & 0.0865 & 0.9993 & 38.6637 & 0.2420 & 0.7766 \\
\hline
\end{tabular}

Where $R$ was the gas constant $=8.314 \mathrm{~J} / \mathrm{mol} / \mathrm{k}, T$ was the temperature in $K, K_{d}^{0}$ was the standard adsorption constant, a plot of $\mathrm{K}_{\mathrm{d}} \mathrm{vs} . \mathrm{C}_{\mathrm{e}}$ was drawn, and from the linear intercept, it could calculate the $K_{d}^{0}$, then the free energy change $\left(\Delta G^{0}\right)$ was calculate by equation 9 ; a plot of $\ln K_{d}$ vs.1/T was drawn, in the same way, from the linear slope and intercept, it could calculate the enthalpy change $\left(\Delta H^{0}\right)$ and entropy $\left(\Delta S^{0}\right)$.

Tab.5 showed the thermodynamic parameters for phenol adsorption on activated carbons at different temperatures.

Table 5 Thermodynamic Parameters For Phenol Adsorption On Activated Carbons

\begin{tabular}{lcccc}
\hline Types & $\begin{array}{c}\text { Temperatures } \\
\left({ }^{\circ} \mathrm{C}\right)\end{array}$ & $\begin{array}{c}\Delta G^{0} \\
\mathrm{~kJ} / \mathrm{mol}\end{array}$ & $\begin{array}{c}\Delta H^{0} \\
\mathrm{~kJ} / \mathrm{mol}\end{array}$ & $\begin{array}{c}\Delta S^{0} \\
\mathrm{~kJ} /(\mathrm{mol} \cdot \mathrm{K})\end{array}$ \\
\hline \multirow{3}{*}{$\mathrm{AC}$} & 15 & -2.070 & & \\
& 25 & -1.854 & -9.806 & -26.789 \\
\hline \multirow{3}{*}{$\mathrm{MAC}$} & 35 & -1.532 & & \\
& 15 & -4.415 & & -26.985 \\
\hline
\end{tabular}


Tab.5 showed that the value of $\Delta G^{0}$ was negative and the value of $|\Delta G|$ was decreased with increase of temperature, which indicated that the adsorption process was spontaneous and the spontaneity of the reaction was weaken at high temperature. The value of $\Delta H^{0}$ and $\Delta S^{0}$ were all negative, so it was an exothermic reaction process of entropy reduction, low temperature was advantageous to adsorption of phenol on ACs, which was consistent with the Langmuir model fitting result. Alkan et al [23] indicated that the $\Delta H^{0}$ of physical adsorption was lower than chemical adsorption that could react when the enthalpy change was between $40-120 \mathrm{~kJ} / \mathrm{mol}$. From Tab.5, the $\Delta H^{0}$ of AC and MAC was -9.806 and -12.022 $\mathrm{kJ} / \mathrm{mol}$, respectively, which was less than the value of $40 \mathrm{~kJ} / \mathrm{mol}$. It could conclude that the adsorption process of activated carbons for phenol was physical adsorption.

Effect of pH: Adsorption capacity of phenol on AC and MAC under different pH conditions was shown in Fig.4 and the effect of $\mathrm{pH}$ on adsorption was different for $\mathrm{AC}$ and MAC. The adsorption performance of phenol on MAC was more sensitive to $\mathrm{pH}$ and had a sharp change within the range of $\mathrm{pH}$ value. The minimum adsorption capacity was obtained in $\mathrm{pH}=11$.

The electrostatic interaction between the adsorbent and the adsorbate was directly affected by the solution $\mathrm{pH}$ [11]. The value of the pHpzc of the AC and MAC was 8.21 and 8.90 , respectively (shown in Tab. 6). When the solution $\mathrm{pH}$ was close to the $\mathrm{pH}_{\mathrm{pzc}}$, the surface electrostatic on ACs was zero, and phenol remained in molecular forms $(\mathrm{pH}<9)$, the $\pi-\pi$ dispersion interaction strengthened [24], which leaded to the best adsorption capacity of $\mathrm{AC}$ and MAC. When the solution $\mathrm{pH}<\mathrm{pH}_{\mathrm{pzc}}$, the charge of activated carbon was positive, the dispersion interaction between the activated carbons and the phenol molecular was reduced, then the adsorption capacity was decreased. When the solution $\mathrm{pH}>\mathrm{pH}_{\mathrm{pzc}}$ and $\mathrm{pKa}$, the charge of activated carbon was negative, the electrostatic repulsion between the activated carbons and the phenol ions was formed, which leaded to the decrease of the adsorption capacity, so it represented the smallest adsorption capacity at $\mathrm{pH}=11$.

Compared with AC, better dispersion interaction was existing on MAC for the lesser acid oxygen-containing functional groups, stronger alkalinity and the hydrophobicity on the surface after modification [12], which increased the physisorption. And compared with other alkaline modified method it was suggested that thermal treatment at high temperature under inert gas followed by contact with dry oxygen at room temperature was the best method to produce basic activated carbons[10]. Moreover, the adsorption process was sensitive to the change of the solution $\mathrm{pH}$ under the high electron density, which made the adsorption process of MAC was more sensitive to solution $\mathrm{pH}$ than AC. From Fig.4, the optimum $\mathrm{pH}$ range was $6 \sim 8$. In the experiment, phenol solution was acidic, $\mathrm{pH}$ value was close to 7 , and the $\mathrm{pH}$ of the reaction solution was not adjusted individually.

Table 6 Changes Of The Surface Chemical Properties Of Activated Carbons

\begin{tabular}{cccccc}
\hline Types & $\begin{array}{c}-\mathrm{OH} \\
/ \mathrm{mmol} \cdot \mathrm{g}^{-1}\end{array}$ & $\begin{array}{c}\text {-COOR } \\
/ \mathrm{mmol} \cdot \mathrm{g}^{-1}\end{array}$ & $\begin{array}{c}-\mathrm{COOH} \\
/ \mathrm{mmol} \cdot \mathrm{g}^{-1}\end{array}$ & $\begin{array}{c}\text { basicity } \\
/ \mathrm{mmol} \cdot \mathrm{g}^{-1}\end{array}$ & $\mathrm{pH}_{\mathrm{pzc}}$ \\
\hline $\mathrm{AC}$ & 0.044 & 0.187 & 0.149 & 0.28 & 8.21 \\
$\mathrm{MAC}$ & 0.003 & 0.043 & 0 & 0.43 & 8.90 \\
\hline
\end{tabular}

\section{Conclusion}

(1) The content of surface acidity oxygen-containing functional groups of activated carbon decreases after modification by thermal treatment at high temperature under $\mathrm{N}_{2}$ flow, while the surface alkaline and $\mathrm{pH}_{\mathrm{pzc}}$ value increase, $\pi-\pi$ dispersion interaction strengthen, meanwhile, the modification is conducive to the increase of the specific surface area and the formation of pore structures, which lead to the improvement of the adsorption capacity. 
The optimum $\mathrm{pH}$ range is $6 \sim 8$.

(2) The adsorption equilibrium of phenol on AC and MAC was achieved after 360min. And the adsorption processes fit well with pseudo-second-order kinetics.

(3) The adsorption isotherms of phenol on AC and MAC fit well with Langmuir model $\left(\mathrm{R}^{2}>0.999\right)$, it belongs to a monolayer adsorption process. The maximum phenol adsorption capacity of phenol on AC and MAC reduces from 123.46 to $103.09 \mathrm{mg} / \mathrm{g}$ and 192.31 to $163.93 \mathrm{mg} / \mathrm{g}$, respectively, with the temperature increase from $15^{\circ} \mathrm{C}$ to $35^{\circ} \mathrm{C}$. It concludes that low temperature is in favor of activated carbon adsorption of phenol.

(4)Thermodynamic parameters $\Delta G^{0} 、 \Delta H^{0}$ and $\Delta S^{0}$ show that the adsorption of phenol on activated carbons is a spontaneous, exothermic reaction process of entropy reduction, and the adsorption is a physical adsorption.

\section{Acknowledgement}

We would like to thank all the reviewers and participants for their carefully critical reading of the manuscripts and useful comments and suggestions. And the project was supported by the Science Foundation of Fujian Province, China (Grant No. 2015Y0072 and 2010Y3011), the Science Foundation of Fujian Environmental Protection Bureau, China (Grant No. 2013R006), and the Foundation for Innovative Research Team of Jimei University, China (No. 2010A007)

\section{References}

1. R. Bhargavi, K. Kadirvelu, N. S. Kumar. Static and Dynamic Adsorption of Phenol from Aqueous Solution Using Spherical Carbon[J]. AIP Conf. Proc. 2013, 1538(78): 78-88.

2. F. Sh. Mohamed, W. A. Khater, M. R. Mostafa. Characterization and phenols sorptive properties of carbons activated by sulphuric acid[J]. Chemical Engineering Journal, 2006, 116: 47-52.

3. A. Chen, G. Zeng, G. Chen, et al. Novel thiourea-modified magnetic ion-imprinted chitosan/ $\mathrm{TiO}_{2}$ composite for simultaneous removal of cadmium and 2,4-dichlorophenol, Chem. Eng. J. 2012, 191: 85-94.

4. K. J. Choi, S. G. Kim, C. W. Kim, et al. Effects of activated carbon types and service life on removal of endocrine disrupting chemicals: amitrol, nonylphenol, and bisphenol-A[J]. Chemosphere , 2005, 58: 1535-1545.

5. C. T. Hsieh, H. S. Teng. Liquid-Phase Adsorption of Phenol onto Activated Carbons Prepared with Different Activated Levels[J]. Journal of Colloid and Interface Science, 2000, 230: 171-175.

6. I. I. Salame, T. J. Bandosz. Role of surface chemistry in adsorption of phenol on activated carbons[J]. Journal of Colloid and interface Science, 2003, 264: 307-312.

7. M. Franz, H.A. Arafat, N.G. Pinto, Effect of chemical surface heterogeneity on the adsorption mechanism of dissolved aromatics on activated carbon, Carbon, 2000, 38 : 1807-1819.

8. C. C. Leng, N. G. Pinto. Effects of surface properties of activated carbons on adsorption behavior of selected aromatics, Carbon, 1997, 35 (9): 1375-1385.

9. J. Przepiórski. Enhanced adsorption of phenol from water by ammonia-treated activated carbon[J]. Journal of Hazardous Materials B, 2006, 135: 453-456.

10. M. F. R. Pereira, S. F. Soares, et al. Adsorption of dyes on activated carbons: influence of surface chemical groups [J]. Carbon, 2003, 41: 811-821.

11. C. S. Ding, F. M. Ni, J. Miao, et al. Study on preparation of ammonia-modified 
activated carbon and its adsorption characteristic for phenol [J]. Journal of Wuhan University of Technology (Transportation Science \& Engineering), 2011, 35(6): 12371241. (In Chinese)

12. G. G. Stavropoulos, P. Samaras, G. P. Sakellaropoulos. Effect of activated carbons modification on porosity, surface structure and phenol adsorption[J], Journal of Hazardous Materials 151, 2008, 414- 421.

13. A. M. Oickle, S. L. Goertzen, K. R. Hopper, et al. Standardization of the Boehm titration: Part II. Method of agitation, effect of filtering and dilute titrant[J].Carbon, 2010,48:3313- 3322 .

14. S. L. Goertzen, K. D. Theriault, A. M Oickle, et al. Standardization of the Boehm titration. Part I. $\mathrm{CO}_{2}$ expulsion and endpoint determination [J]. Carbon, 2010, 48:1252 -1261 .

15. G. F. Liu. Study on adsorption efficiency and mechanism of phenolic endocrine disrupting chemicals on activated carbons with various surface modification [D]. Harbin, Harbin Institute of Technology, 2008. (In Chinese)

16. O. B. Yang, J. C. Kim, J. S. Lee, et.al. Use of activated carbon fiber for direct removal of iodine from acetic acid solution[J]. Industrial Engineering Chemistry Research, 1993, 32 (8): 1692-1697.

17. Y. S. Ho, J. C.Y. Ng, G. McKay. Kinetics of Pollutant Sorption by Biosorbents: Review [J]. Separation and Purification Methods. 2000, 29(2): 189-232.

18. S. K. Bhatia, F. Liu, G. Arvind. Effect of Pore Blockage on Adsorption Isotherms and Dynamics: Anomalous Adsorption of Iodine on Activated Carbon[J]. Langmuir, 2000, 16(8): 4001-4008.

19. W. J. Jr. Weber, J. C. Morris. Equilibria and capacities for adsorption on carbon[J]. Journal of Sanitary Engineering Division. Proceedings of the American Society of Civil Engineers, 1963, 89: 31-59.

20. Ö. Gerçel, A. Özcan, A. S. Özcan. Preparation of activated carbon from a renewable bio-plant of Euphorbia rigida by $\mathrm{H}_{2} \mathrm{SO}_{4}$ activation and its adsorption behavior in aqueous solutions[J].Applied Surface Science, 2007, 253: 4843- 4852.

21. B. Agarwal, C. Balomajumder, P. K. Thakur. Simultaneous co-adsorptive removal of phenol and cyanide from binary solution using granular activated carbon[J]. Chemical Engineering Journal, 2013, 228: 655-664.

22. J. M. Duan, J. M. Lin, H. D. Fang, et al. Adsorption characteristic of modified steel-making slag for simultaneous removal of phosphorus and ammonium nitrogen from aqueous solution [J].Chinese Journal of Environmental Engineering, 2012, 6(1): 201-205. (In Chinese)

23. M. Alkan, Ö. Demirbaş, S. Çelikçapa, et al. Sorption of acid red 57 from aqueous solution onto sepiolite[J]. Journal of Hazardous Materials, 2004, 116(1-2): 135-145.

24. R. W. Coughlin, F. S. Ezra. Role of Surface Acidity in the Adsorption of Organic Pollutants on the Surface of Carbon [J]. Environment Science technology, 1968, 2(4): 291-297. 